\title{
O CORPO NA ESCRITA DIARÍSTICA DE LÚCIO CARDOSO E WALMIR AYALA
}

\section{THE BODY IN THE DIARISTIC WRITING OF LÚCIO CARDOSO AND WALMIR AYALA}

\begin{abstract}
Daniel da Silva Moreira
RESUMO: Este ensaio dedica-se a pensar a presença do corpo e de seus desdobramentos na escrita diarística de Lúcio Cardoso e de Walmir Ayala. Ambos os autores desenvolveram, entre os anos de 1940 e 1960, uma escrita pioneira que colocou em cena, pela primeira vez na literatura brasileira, a existência do homossexual e da homossexualidade a partir de uma perspectiva da primeira pessoa. Assim, buscase aqui compreender como se dá a negociaçâo do espaço simbólico que esse corpo, colocado tradicionalmente à margem da sociedade, vai passar a ocupar uma vez que se ouse propor sua existência, que ele seja colocado em evidência.
\end{abstract}

PALAVRAS-CHAVE: Corpo. Homossexualidade. Diário. Literatura brasileira.

ABSTRACT: This essay aims to think on the presence of the body and of its ramifications in the diaristic writing of Lúcio Cardoso and Walmir Ayala. Both authors developed, between the 1940's and the 1960's, a pioneering writing that put in evidence, for the first time in Brazilian literature, the existence of the homossexual and of the homosexuality from the perspective of the first person. Therefore, this text seeks to understand how occurs the negotiation of the symbolic place that this body, traditionally put aside from the society, will take once someone dares to suggest its existence, once it is put in evidence.

KEYWORDS: Body. Homosexuality. Diary. Brazilian literature. 
Escrever sobre o corpo e sobre a sexualidade na primeira pessoa toca, obviamente, naquilo que há de mais íntimo e sensível na vida do sujeito. De acordo com Michel Braud, "A sexualidade é, como a doença (e sem dúvida bem mais que ela), excluída do discurso social. É um dos domínios mais privados do sujeito. Sua evocaçăo é muitas vezes alusiva, especialmente em diários do século XIX."1 (BRAUD, 2006, p. 86-87, traduçấo minha). Apesar dessa exclusăo e da forma alusiva de ser abordada na literatura de um modo geral, no diário, gênero associado frequentemente à confissấo e à escrita daquilo que é secreto, seria de se esperar que a sexualidade encontrasse um espaço de expressăo, mas a situaçăo năo é tăo simples:

(...) o diário tem, por definiçăo, vocaçăo para acolher todos os discursos íntimos, e por conseguinte aquele sobre a sexualidade, uma vez que ele se constitui numa das experiências do sujeito. Mas uma reticência indefinida retém o diarista no limiar da escrita, como se essa atividade permanecesse íntima demais para ser aí registrada, ou como se năo houvesse termos adequados disponíveis para descrever com exatidăo e sem ser pudico. ${ }^{2}$ (BRAUD, 2006, p. 87, traduçăo minha)

E, assim, parece haver uma hesitaçăo ao escrever sobre sexo e sobre o corpo, como se a linguagem - ferramenta a que está bem habituado o diarista, sobretudo sendo ele escritor - entrasse em crise e năo fosse adequada para representar isso que é tăo profundo e pessoal. Entre alusóes e polissemias, entre vulgaridade e obscenidade, o diarista vai buscar uma forma de colocar por escrito seu corpo e sua atividade sexual (BRAUD, 2006, p. 87). Braud diz que, se por um lado os diaristas do século XIX săo bastante pudicos sobre a própria sexualidade em seus escritos, os contemporâneos dificilmente se furtam completamente ao assunto:

Já os diaristas contemporâneos, esses, raramente guardam um silêncio absoluto sobre sua sexualidade, mas manifestam em geral uma certa desconfiança diante do risco de condescendência que se liga à sua evocaçăo. Embora anotem fragmentos de descriçăo, eles os integram a um discurso de si no qual ganham sentido. Năo se trata, ou nâo apenas, de encontrar a satisfaçấo sexual passada através da precisăo da representaçấo (...) mas de integrá-la a uma narraçấo de si que se liga ao valor de suas experiências. ${ }^{3}$ (BRAUD, 2006, p. 88, traduçăo minha)

Isso equivale a dizer que, na contemporaneidade, ainda que haja menos tabus relativos a uma escrita que coloque em cena a sexualidade, prevalece a observância de que quaisquer referências a essa dimensăo da vida, mais do que representadas

1 No original: “La sexualité est, comme la maladie (et sans doute plus qu'elle encore), exclue du discours social.C'est l'un des domaines les plus privés du sujet. L'évocation en est souvent allusive, particulièrement dans les journaux du XIXe siècle.".

2 No original: “(...) le journal a par définition vocation à accueillir tous les discours intimes, et donc celui sur la sexualité en tant qu'elle constitue l'une des expériences du sujet. Mais une réticence indéfinie retient le diariste sur le seuil de l'écriture, comme si cette activité demeurait trop intime pour y être consignée, ou comme s'il n'y avait pas de termes adéquats disponibles pour la décrire avec exactitude et sans pudibonderie.".

3 No original: "Les diaristes contemporains, eux, gardent rarement un silence absolu sur leur sexualité, mais manifestent en général une défiance certaine vis-à-vis du risque de complaisance qui s'attache à son évocation. S'ils notent encore des bribes de description, ils les intègrent à un discours de soi dans lequel elles prennent sens. Il ne s'agit pas, ou pas seulement, de retrouver la jouissance sexuelle passée par la précision de la représentation (...), mais de l'intégrer à une narration de soi qui s'attache à la valeur de ses expériences.". 
pormenorizadamente, deveriam estar ligadas a algo maior, a experiências fundamentais para a constituiçăo do sujeito que escreve. Uma vez que, como o próprio Braud afirma adiante, "A sexualidade é um signo do sujeito e de sua identidade."4 (BRAUD, 2006, p. 88, traduçăo minha), para que ela seja bem aceita no mundo da escrita é melhor que se mostre bem claramente sua ligaçăo com a constituiçăo de uma identidade. Ainda de acordo com o autor, é recorrente entre os diaristas contemporâneos reivindicarem mesmo "(...) sua sexualidade: sua orientaçâo sexual e, mais amplamente, o lugar, as formas e o valor da sexualidade em sua existência." ${ }^{\prime \prime}$ (BRAUD, 2006, p. 88, traduçăo minha). Essa reivindicaçăo vai ter, certamente, um valor especial junto a diaristas homossexuais, para quem uma escrita que busque representar suas interaçóes físicas com o outro será transgressora, além das razôes óbvias, por conta do próprio gênero desse outro. No diário, a sexualidade desempenha também um papel importante, serve a mostrar a vida em toda sua exuberância, serve a deixar claro que se existe e que a própria vida é plena (BRAUD, 2006, p. 89). A sexualidade, assim, “(...) mantém a angústia da morte à distância e mostra o rosto da morte. Ela afirma a existência, a presença de si no corpo a corpo amoroso, num contexto de aniquilaçáo e morte."6 (BRAUD, 2006, p. 89, traduçâo minha). Alguns teóricos vâo propor, ainda, que o diário acaba se tornando uma espécie de corpo acessório para o diarista. Sérgio Barcellos vai dizer que "O diário como um segundo corpo, onde se rememora o feito, o vivido, o sentido, onde se imagina a vida e se projeta um futuro, é um corpo com seu DNA próprio." (BARCELLOS, 2011, p. 82). Isto é, o diário serve a reavivar as experiências com o corpo do passado e a antecipar as do futuro, como num segundo corpo que fornece um suplemento de gozo. Jean-Louis Cabanès, em L'écrivain et ses travaux au miroir des journaux intimes [0 escritor e suas obras no espelho dos diários], tratando dos diários dos irmáos Goncourt, mostra como o corpo participa daquilo que se considera como íntimo:

Poderíamos inicialmente lembrar que, para os dois irmăos, o íntimo é também o corpo, seus humores, suas vísceras, suas excreçôes. É o sangue que falta, é a linfa que abunda, săo os nervos hipersensibilizados. Compreender os trabalhos do escritor é compreender esse enraizamento corporal mas também analisar o impacto do escrito sobre a carne. ${ }^{7}$ (CABANÈS, 2009, §̧01, traduçăo minha)

Assim, o que está em jogo é nâo somente a representaçâo do corpo através da escrita, mas também o modo como o ato de escrever, a escolha de uma vida de escritor e de colocar por escrito essa vida através do diário incrustam suas marcas no corpo desse sujeito. Marion Krauthaker, num texto sobre a escrita autobiográfica da autora hermafrodita francesa Herculine Barbin, trata, ainda que superficialmente, sobre a construçáo simbólica do corpo em nossa sociedade, especialmente através da obra Corpos que importam, em que Judith Butler demonstra que a construçâo do corpo

$4 \quad$ No original: "La sexualité est un signe du sujet et de son identité.".

5 No original: “(..) leur sexualité: leur orientation sexuelle et plus largement la place, les formes et les valeurs de la sexualité dans leur existence.".

6 No original: “(...) tient l'angoisse de mort à distance et montre le visage de la mort. Elle atteste de l'existence, de la présence à soi dans le corps à corps amoureux, sur fond de néant et de disparition.".

$7 \quad$ No original: "On pourrait tout d'abord rappeler que pour les deux frères, l'intime, c'est aussi le corps, ses humeurs, ses viscères, ses excrétions. C'est le sang qui fait défaut, c'est la lymphe qui surabonde, ce sont les nerfs hyperesthésiés. Rendre compte des travaux de l'écrivain, c'est rendre compte de cet enracinement corporel mais aussi analyser le retentissement de l'écrit sur la chair.". 
humano é fruto de uma operaçăo de diferenciaçăo que produz o humano e o inumano, limitando os indivíduos em sua experiência do social (KRAUTHAKER, 2016, p. 19). Um ponto importante da discussăo levantada por Krauthaker é aquele referente ao modo como o texto autobiográfico pode ser de fundamental importância para todos aqueles que sâo um desvio da norma, ela diz: "Uma vez que os "corpos que importam" săo aqueles da norma, o "verdadeiro sexo" se esconde forçosamente por trás das aparências."8 (KRAUTHAKER, 2016, p. 19, traduçâo minha). Assim sendo, o processo de investigaçăo de si propiciado pela escrita autobiográfica torna-se indispensável à compreensâo de uma identidade que, escapando ao que é central, ao que "importa" e que consequentemente tem sua representaçăo garantida através dos canais oficiais, deve ser descoberta ser a ser, praticamente a partir do zero, removendo da vista tudo que é aparência e tudo que é representaçâo dos corpos dominantes.

Para entender melhor essa dinâmica dos corpos e das sexualidades no âmbito da escrita diarística, creio que seja de fundamental importância partir para a leitura de alguns diários. No presente ensaio, escolho fazê-lo em dois autores fundamentais para as escritas de si no Brasil, Lúcio Cardoso e Walmir Ayala ${ }^{9}$. Esses dois autores, entre o fim dos anos de 1940 e o início dos anos de 1960, ousaram, pela primeira vez, romper a longa tradiçáo de silenciamento a que esteve sujeito o homossexual na literatura brasileira e o fizeram a partir de sua escrita diarística, isto é, sob uma perspectiva da primeira pessoa, o que aumenta consideravelmente o risco e a ousadia desse ato ${ }^{10}$.

A eleiçăo do diário como gênero de expressăo por esses autores se deve, em parte, ao modo como essa prática se coloca a serviço de suas vidas e de suas obras literárias, articulando-se como um espaço seguro de construçăo de uma determinada imagem de si, permitindo a elaboraçăo de um perfil que, de acordo com os objetivos, vivências e condiçôes de seus autores, privilegia ou oculta traços do sujeito. O diário permite a Cardoso e Ayala a criaçâo de um espaço de auto-hospitalidade capaz de acolher, sem as regras e preconceitos do mundo exterior, um discurso da margem, nesse caso, o da homossexualidade. Se uma das grandes estratégias de marginalizaçăo é o silenciamento, a interdiçâo de discurso e de representaçôes simbólicas, o diário permite que o sujeito se veja como tal e, ainda mais importante, que se inscreva textualmente no mundo, adquirindo justamente aquilo que lhe é normalmente negado: a voz e a existência simbólica.

A escolha da escrita diarística está relacionada, também, à afinidade que esses autores desenvolveram com a escrita de alguns autores franceses, como Marcel Jouhandeau, Julien Green e, em especial, André Gide. Muito mais do que um modelo textual para a própria escrita, Gide e os outros autores de escritos de si vâo emergir como símbolos de uma postura diante do mundo e da escrita, representando um modelo emblemático, tanto no que tange à temática abordada (seu desejo e suas experiências homossexuais) quanto na seleçăo de um gênero supostamente "menor", alçado à categoria de gênero "maior" à época em que os autores começam a manter seus diários

8 No original: "Puisque les "corps qui comptent" sont ceux de la norme, le "vrai sexe" se cache forcément derrière les apparences.".

9 Nota a ser adicionada após a avaliaçăo cega por pares, pois seu conteúdo poderia revelar a autoria do texto.

10 Nota a ser adicionada após a avaliaçăo cega por pares, pois seu conteúdo poderia revelar a autoria do texto. 
com maior constância (Gide tem seus diários publicados em 1939 na Bibliothèque de la Pléiade e em 1948 recebe o Nobel). Nesse processo, o autor consagrado tem a funçâo de tornar os caminhos menos difíceis, fornecendo uma forma de expressáo possível para a homossexualidade. Assim, Cardoso e Ayala văo se aproximar e se apropriar de uma escrita oblíqua - uma forma indireta de se referir à homossexualidade -, característica do diário gideano, para tratar da homossexualidade, para abordarem o tema em seus próprios textos.

Todavia, a imagem do homossexual e as ideias sobre a homossexualidade que apresentam os diários de Lúcio Cardoso e Walmir Ayala săo ou bastante equivocadas, ou marcadamente negativas. E năo há como se esperar algo diferente de algo escrito nessa época, uma vez que o orgulho de ser gay só viria a ser inventado muito mais tarde. Por outro lado, a forma como esses três diaristas năo se furtaram a colocar em seus diários - que eles tinham o expresso intuito de publicar -, a temática (e por vezes mesmo a defesa, na medida do possível) da homossexualidade, é algo que pode ser considerado como um grande avanço dentro da literatura brasileira. É a reivindicaçâo de um espaço, de uma existência simbólica - requerida pela primeira vez por alguém ocupando um lugar de fala identificado com aquele por quem se advoga direitos e espaço - secularmente negados ao sujeito homossexual.

Seus diários dăo espaço, finalmente, ao amor, ao registrarem amores praticamente impossíveis em suas épocas, carregando, ainda, todas as marcas deixadas por essa exclusăo. Cada um à sua maneira, Cardoso e Ayala parecem nunca terem realmente desistido de ter para si uma parcela de amor que a sociedade queria lhes negar. Mas fizeram bem mais que isso, escreveram sobre essa busca, deixaram testemunhos assinados para a posteridade, capazes de fazer lembrar tanto da possibilidade de existência desse "amor que năo ousa dizer seu nome", quanto da angústia, da tristeza e da solidăo de saber, dia após dia, que, na realidade de seu próprio tempo, esse amor náo pode ser mais nada do que circunstancial, fragmentado, cabotino, enfim, marginal.

Nos diários de Cardoso e Ayala, o corpo e a sexualidade estăo presentes de modos distintos, às vezes mais, às vezes menos claramente. Em comum, todos eles têm de relegarem esse plano da existência humana a um espaço marginal em sua escrita. Vejase, por exemplo, o caso de Lúcio Cardoso, em cujo diário há uma decisāo expressa no sentido de torná-lo um texto que trate apenas do que o diarista considera de interesse público (Cf. CARDOSO, 2012, p. 358), isso porque “(...) jamais deveríamos conhecer o particular da vida dos grandes homens" (CARDOSO, 2012, p. 243, 07 maio 1950). Essa separaçấo entre público e privado é expressa também por Lúcio Cardoso na escolha entre escrever sobre fatos (que seriam matéria do diário dos outros) ou sobre ideias e sentimentos (a matéria do seu diário) (Cf. CARDOSO, 2012, p. 351). Numa entrada que encerra uma parcela de seus diários, Cardoso repassa aquilo que já foi escrito e comenta a razâo de nâo ter se detido em seu texto sobre a "questâo sexual":

A questáo sexual, por exemplo, que alguns leitores provavelmente reclamariam, que adiantaria estampá-la, destituída de força, apenas para catalogar pequenas misérias sem calor e sem necessidade? Mas por outro lado, procurei, para com as minhas ideias e os meus sentimentos, ser tăo exato quanto possível. (CARDOSO, 2012, p. 358, 17 mar. 1951) 
O diarista reconhece que, embora haja um suposto interesse de um leitor potencial por revelaçôes e confissóes de cunho bastante íntimo, qualquer avanço nesse sentido seria um mero desperdício de energia, que mostraria apenas o que é inferior, as "pequenas misérias" do ser humano. No lugar disso, Cardoso propóe que vale mais a exatidâo sobre sentimentos e ideias. Essa é uma forma de se relacionar com o corpo - e com tudo a ele ligado - que vai ditar a postura do autor em praticamente toda a extensáo de seus escritos diarísticos:

O que náo suporto é que se queira estabelecer a vida sexual - por mais elevada que ela seja - como regra determinada, como realizaçăo de uma vida total. / O homem é sempre mais variado e é impossível ficar em uma parte só, ainda quando essa parte se manifestar com genialidade. Năo adianta fingir nem enganar: sabemos muito bem que a vida sexual náo é tudo. / O erotismo é dessas coisas muito particulares que dificilmente consentimos em tornar públicas. (CARDOSO, 2012, p. 108, s.d.)

Aparentemente, Cardoso foi defrontado com a ideia de que uma vida plena deveria incluir também uma vida sexual. Reagindo negativamente a ela, o diarista chega mesmo a escrever que o sexo náo é tăo significativo e destaca o fato de o erotismo ser algo que raramente deixa a vida íntima e vem a público. Se o sexo é dispensável, na verdade é porque a concepçăo que Cardoso tem da totalidade das interaçôes humanas coloca-o em complementariedade em relaçâo a outros valores mais elevados: "Năo, a carne é inútil, impossível é contentarmo-nos com tăo pouco. O único caminho é ser casto, ante a sensaçâo de pobreza que a posse física nos transmite." (CARDOSO, 2012, p. 203, 15 set. 1949). A interaçăo meramente física convida à castidade, para evitar, assim, um empobrecimento da experiência e, por consequência, da constituiçấo do sujeito. Essa mesma ideia se encontra também numa entrada escrita cerca de seis anos depois:

Aproveito todas as aquisiçōes da idade: afasto-me da carne pura e simples, sentindo que nela năo há prazer e nem enriquecimento, mas somente melancolia e pobreza. Ah, existe um momento em que ser casto náo é difícil - e a ele eu me atiro com todas as forças do ser. Nâo, năo se pode imaginar a necessidade que eu tenho de pureza e de tranquilidade - minha impressăo é a de que recomeço a viver. (CARDOSO, 2012, p. 413, 31 out. 1955)

O que incomoda, nesse caso, nâo é a carne, mas quando ela vem "pura e simples", ou seja, quando o sexo é apenas ele mesmo e năo traz uma experiência mais ampla, provavelmente de afeto e partilha intelectual, que se contraporia à "melancolia e pobreza". O sexo tomado isoladamente é desencadeador de intranquilidade e impureza, numa analogia que vai se aproximando cada vez mais dos valores que o cristianismo costuma atribuir ao corpo e à sexualidade. Por outras vezes, é preciso que se diga, Cardoso aparece em seu diário discutindo a sexualidade sem tantos cuidados. Por ocasiăo da leitura de $\mathrm{O}$ amante de Lady Chatterley, de D. H. Lawrence, é possível encontrar um diarista um pouco diferente das outras entradas que destaquei acima, que assume mesmo algumas preferências sexuais:

Lawrence - 0 amante de Lady Chatterley. / Afasto-me de Lawrence quando ele insiste tanto em normalidade e sanidade de sexo, no prefácio de seu livro. 0 sexo sadio e feito em plena consciência me atrai muito como espetáculo, já foi mesmo um ideal meu e o vejo com muita simpatia. Mas o equilíbrio e a normalidade como objetivo para o exercício do sexo é coisa que realmente náo posso admitir. Prefiro uma posiçáo sem leis, até de libertinagem, de sexo pelo sexo, e năo de sexo pela 
naturalidade. / Nâo que eu compreenda o sexo como algo obscuro que só vem à luz com escândalo; simplesmente quero o sono mais louco, aproveitando melhor as suas imensas possibilidades. (CARDOSO, 2012, p. 106, s.d.)

O sexo como hábito, como prática higienista, dentro de uma rotina e da normalidade năo interessa mais ao diarista, para ele valeria mais o sexo pelo sexo - esse mesmo que anteriormente mostrei que ele relegava a um segundo plano -, o sexo como uma "posiçấo sem leis", libertina. Uma posiçâo um tanto dúbia - e faz parte da escrita diarística, sobretudo aquela mantida durante muitos anos a fio, a mudança de opiniăo sobre um determinado assunto -, mas que encontra eco num outro trecho do diário, em que Cardoso parece nâo estar tăo disposto a renunciar à carne: "Nâo importa que uma dialética trágica e destruidora pareça associar-se tăo frequentemente à vida sexual. A carne é coisa a que năo se renuncia. Deve-se arriscar o corpo também e nâo apenas o espírito. Náo me importa o que acontecer. Tudo será apenas "consequência"." (CARDOSO, 2012, p. 104, s.d.). No lugar da renúncia, nessa entrada domina o convite a ousar nâo somente através do espírito, mas também do corpo, pouco importando o preço a pagar por esse ato. Para Lúcio Cardoso, em síntese, a posiçăo dominante é a de que o sexo só serve se vem acompanhado de algo mais elevado, que sirva a um apuramento da experiência do sujeito. O sexo e a sexualidade interessam pouco à escrita, melhor é que permaneçam na esfera íntima e que cedam lugar a assuntos considerados, senăo mais nobres, de maior interesse para a posteridade e para a constituiçăo de um perfil de intelectual. Esse é um claro compromisso com a ideia, sobre a qual tratei anteriormente, de que há, entre os escritores contemporâneos, uma grande preocupaçâo de que a sexualidade náo esteja presente de forma gratuita na escrita autobiográfica, que seja justificada e legitimada por sua participaçấo num tipo de experiência mais elevada, que contribua para a composiçấo da identidade do sujeito que escreve. Desse modo, năo é de se estranhar a ausência de grandes incursôes por uma escrita da sexualidade por parte de Cardoso, talvez ele o fizesse se julgasse que houvesse algo significativo a contar. Como parece nâo haver algo que se adeque a seus modelos, o diarista desenvolve no lugar disso sua teoria de que o sexo por si mesmo é algo inferior e que é melhor que năo seja mencionado. Por outro lado, tudo isso pode ser também motivado por uma impossibilidade de comunicar por escrito suas experiências sexuais. Se a relaçâo afetiva entre duas pessoas do mesmo sexo já choca, o que se diria no Brasil dos anos de 1950 e 1960 sobre descriçóes bastante plásticas de suas relaçóes físicas? Nesse ponto, pode-se pensar também numa possível tentativa, ainda que năo declarada, de retirar a atençăo da relaçăo homossexual concebida apenas como física, já que paira sobre o homossexual um espectro de imoralidade. Calar-se sobre certos aspectos sobre os quais há expectativa é, em certa medida, uma tentativa de mudar essa imagem, de ampliar a forma como o senso comum concebe as relaçōes homoeróticas.

No que diz respeito às questôes sobre o corpo, o sexo e a sexualidade, os diários de Walmir Ayala săo, definitivamente, bastante diferentes dos de Lúcio Cardoso. Apesar de terem quase a mesma idade, serem muito próximos intelectualmente, conviverem nos mesmos meios, terem referências culturais semelhantes e escrevem no mesmo momento, Ayala é muito mais aberto sobre seus questionamentos e mesmo sobre questóes práticas ou cotidianas em sua escrita. Já no primeiro volume, ao lado do tema mais importante, o amor, é possível encontrar algumas referências diretas a um prosseguimento mais físico dos muitos amores que passam por sua escrita. A espera de 
um amante que náo aparece faz com que o corpo chame a atençăo do diarista: "Noite. Espero um telefonema. Minha carne arde e eu busco um motivo para ser infiel a J. No fundo nâo é o motivo que me inquieta, mas a necessidade de ser infiel." (AYALA, 1962, p. 79, 20 ago. 1958). A "carne arde" entre o desejo de ser infiel e a culpa por trair J. Alguns meses depois, Ayala passa a noite com alguém identificado pela inicial E., a quem contempla, consciente de sua fragilidade: "Tenho que dormir E. está ao alcance da minha mâo para uma carícia ou para a morte. Eu năo tocaria nele se năo fosse para torná-lo eterno, além de mim..." (AYALA, 1962, p. 114, 26 nov. 1958). A história transcende o mero encontro casual e, alguns dias depois, o diarista tem o amado novamente em seu leito, e o observa, deslumbrado: "E. é o ser mais bonito que eu vi adormecido. Incluo nisso os gatos que amei, os pássaros, e mesmo um coelhinho branco que me roubaram numa sexta-feira santa." (AYALA, 1962, p. 114, 30 nov. 1958). Por outras vezes, ainda no mesmo volume do diário, a linguagem usada para tratar dos encontros físicos é mais contida, como na seguinte passagem, em que o diarista flerta com um homem nâo identificado nem ao menos por iniciais:

Em amor gosto que me resistam, constatei isto ontem diante de um entusiasmo que, pela facilidade se transformou em simples aventura. E uma aventura năo deixa raízes, a fraqueza me desinteressa. Sabia que me observava, que esperava um sinal, um gesto, uma intimidade, e náo concedi propositadamente, e juro que isto năo me faria mais feliz, por isto náo concedi. Se eu amasse seria diferente... (AYALA, 1962, p. 122, 12 dez. 1958)

A cena descreve um encontro bastante casual, uma tentativa de conquista que se empreende praticamente sem palavras, um "entusiasmo", como diz o diarista, mas que năo vai adiante pois ele diz também preferir a resistência, o desafio, artifícios dispensados unicamente se houvesse amor envolvido na situaçăo. No segundo volume dos diários de Ayala, as mençôes à sexualidade e ao amor físico continuam, mas năo há uma obsessăo pelo tema, o amor vem muito antes dele. Isso me parece intimamente ligado à proposta elaborada no primeiro volume, de se conquistar um lugar para a homossexualidade através do amor e da renúncia física. Assim, evita-se ao máximo o registro meramente realista do sexo no diário de Walmir Ayala:

\footnotetext{
Hoje tenho um encontro à meia-noite. Náo será um encontro carnal - se fosse eu náo registraria aqui, náo interessam além da dualidade combativa que armam. Mas o encontro é com uma pessoa fundamental - sob um certo sentido a mais fundamental agora. Eu náo saberei como levar o copo aos lábios. Conversaremos assuntos os mais alheios ao problema da nossa alma. Ficarei confuso sem saber onde pôr as măos, como olhar, com confissóes novas aflorando mudas. (AYALA, 1963, p. 88,29 jan. 1960)
}

O diarista declara a decisăo expressa de náo passar para a escrita de seu texto aquilo que seja simplesmente pertencente a um plano carnal, o que me parece estar relacionado à deliberaçấo consciente de advogar por uma causa, indefensável, para ele, se o seu defensor se permite perder somente no desejo físico. No caso do encontro em questăo, é possível notar que há toda uma preocupaçăo do diarista em destacar que se trata de uma "pessoa fundamental" e em descrever sua postura de deslumbre e afeto em relaçấo a ela. Dentro desse contexto, as "aventuras carnais" vấo acabar sendo associadas, inevitavelmente, ao pecado e à culpa: "O que fiz da minha noite? Uma aventura carnal me dá a maior sensaçăo de vazio. O pecado é isto, relacionar-se por distraçâo, 
para violentar-se, dar vasăo ao instinto para profanar um pensamento que persistia fiel. Hoje pequei." (AYALA, 1963, p. 33, 08 mar. 1959). O sentimento de vazio, de estar pecando, cometendo uma violência contra si mesmo, enfim, a atribuiçáo de tudo que é negativo ao sexo feito fora de uma relaçăo, vấo persistir, afinal sâo motivados por uma verdadeira "sede do sexo": “O que M. L. compóe para si mesmo, humanamente: esta sede do sexo que o atormenta (e que a mim também atormenta, mais moderadamente - por isto ouso ventilar)." (AYALA, 1963, p. 45, 31 maio 1959). Essa tensăo, esse tormento causado pelo desejo, convive, no diário, com cenas que descrevem afeiçăo e ternura, como a registrada pela entrada adiante, em que Ayala faz uma carícia furtiva no amante da vez:

Ontem eu estava pleno de amor. Caminhávamos fraternalmente lado a lado. No bar náo resisti à tentaçáo de lentamente acariciar-lhe os cabelos, como se faz com uma criança; depois, furtivamente passei-lhe as máos nas costas. Nada mais. É um amor com prazo marcado. Sei que partirá logo. (AYALA, 1963, p. 45, 30 maio 1959)

Próximo ao fim do segundo volume do diário, contudo, o diarista parece se aproximar de uma definiçăo do que seria uma relaçăo equilibrada e que satisfizesse plenamente seus ideais: "O amor mais perfeito seria aquele que incluísse uma profunda amizade. Como acontece com E. (...) Para a perfeiçăo só faltou a impossivelmente certa relaçấo sexual." (AYALA, 1963, p. 109, 21 abr. 1959). Dessa maneira, o relacionamento ideal seria constituído por amor, amizade e sexo, algo que se aproxima muito do que ele acreditava ter, naquele momento, com E., apesar de faltar o último dos elementos. No terceiro e último volume dos diários, Ayala, ainda que quase invariavelmente proponha um amor constituído de renúncia carnal, faz constantes incursōes no terreno do amor físico, sempre, ou quase sempre, relacionando a dimensăo física, o corpo, ao pecado, ao crime, ao erro e à perturbaçâo do espírito: "Ontem à noite amei um corpo magnífico. Quis acreditar que precisava disso e representei um papel de amante. Na realidade nâo entendia aquele corpo. (...) Me arrependo depois de cada aventura e sinto atraçáo permanente pelos corpos." (AYALA, 1976, p. 12-13, 27 jun. 1960). O encontro amoroso traz, mais uma vez, o arrependimento, mesmo que junto năo venha a desistência de amar novos corpos. Em outra passagem, a realizaçấo física é associada a um verdadeiro suplício: "Uma aventura amorosa de há três dias atrás deixa uma dor mansa e suportável em minha carne. (...) Há no ato sexual todo um ritual de crucificaçăo." (AYALA, 1976, p. 113, 29 set. 1961). O sexo é comparado, assim, à crucificaçăo, castigo reservado pelos antigos romanos especialmente àqueles que questionavam o poderio de Roma e que carrega, obviamente, um forte significado no mundo cristăo. Em Walmir Ayala, o corpo e o amor físico náo sáo inferiorizados por serem, apesar de satisfatórios, apenas um ponto de passagem para algo que se considere superior, o amor espiritual. Năo é só isso, o plano físico é negligenciado, associado ao mal e deve ser absolutamente sublimado; o que vale única e exclusivamente é o amor espiritual e o entendimento intelectual entre duas pessoas. O sexo é banal, mesmo que ainda exerça controle sobre sua existência: "O sexo me atinge em sua banalidade, me obriga a comunhăo de desespero, enquanto o amor sobrenada os destroços, um amor que ninguém pressente, que se quer absoluto e por isso perde a superfície que lhe concedem, tâo precária e soturna." (AYALA, 1976, p. 71, 04 abr. 1961). O amor se opóe ao sexo, sendo representado como uma espécie de salvaçâo. O corpo é também tomado como um caminho desagradável para a realizaçăo do amor: "Se eu pudesse dialogar apenas com a tua alma! É inútil, é só através de teu corpo 
magnífico que posso imaginar a alma, e sem este caminho físico eu estaria condenado a uma eternidade de trevas mais abominável que a morte." (AYALA, 1976, p. 71, 04 abr. 1961). Apesar disso, a dimensăo física é uma realidade à qual nâo se pode escapar e o diarista parece se conformar com a ideia de que ela é tudo que se pode realmente conhecer e alcançar no outro, sem ela tudo seria somente "uma eternidade de trevas mais abominável que a morte". Apenas alguns dias depois, Ayala vai registrar, com muito menos conflito, que o corpo seria o meio de se atingir o amor:

O corpo é sempre o meio pelo qual se chega ao amor. Lembro seus olhos claros, sua luz mansa, seu sorriso, sua carne de pétala e amêndoa; lembro seus pés, seus tornozelos, seu andar, suas espáduas que sáo a primavera; lembro a linha ingênua e vigorosa do seu braço e suas máos perfeitas onde se consuma a verdadeira glória de uma fidalguia original. (AYALA, 1976, p. 73, 09 abr. 1961)

E, alguns meses depois, o diarista vai propor que năo se misturem o corpo e a alma, duas instâncias irreconciliáveis: "O amor. Certamente năo há como imiscuir o corpo e a alma nesta luta. Ama-se a alma, com a alma. O corpo é o sinal de que a alma existe, e reflete visualmente particularidades desta alma." (AYALA, 1976, p. 116-117, 11 nov. 1961). O próprio corpo também é levado em conta pelo diarista, mas numa perspectiva que o considera uma máquina defeituosa, fadada ao mau funcionamento e à decomposiçăo:

Há dias em que me cansa carregar este corpo. Já tenho uma tal noçăo do apodrecimento que me espera por toda a eternidade da minha carne, que seria justo ter recebido a dádiva de um corpo perfeito. E como entregar ao ser amado esta máquina que falha, que se fatiga, que sofre? Isto jamais frutificaria o deus que 0 amor reclama. (AYALA, 1963, p. 88-89, 29 jan. 1960)

A consciência da efemeridade da vida, do destino que aguarda todos os corpos, interferem profundamente na forma de se relacionar com o outro, afinal, como oferecer ao amado, em sacrifício ou em dádiva, algo que se reconhece falho e perecível? Para Ayala, a entrega amorosa requereria uma oferta perfeita, capaz de fazer com que se desenvolvesse perfeitamente o elemento de divindade que ele via no amor. Por fim, a "máquina desarranjada" do corpo incomoda:

Os sintomas de futuras doenças se fazem visíveis para mim, e resisto a esta mágoa moral de entregar a um médico a aceitação da minha máquina desarranjada. A humanidade deveria nascer perfeita e um dia se apagar como se apaga uma luz, sem os apodrecimentos, as falhas de coraçăo, os cânceres. É triste tomar conhecimento da matéria corruptível que sustenta o nosso espírito e que, por mais iluminados que sejamos, só nos resta para entregar à morte um triste despojo fétido e desprezível. (AYALA, 1976, p. 104, 11 ago. 1961)

A ciência da declinaçăo do corpo com o avanço da idade faz mesmo imaginar um novo sistema de envelhecimento, em que o desaparecimento se fizesse instantaneamente, sem a via-crúcis da doença. A relaçăo com o próprio corpo é, dessa maneira, mediada pelo outro, o corpo serve a encontrar a alteridade, ao amor, e náo se torna uma grande questăo para sua escrita a năo ser que comece a falhar, que comece a dar indícios de que a morte chegará um dia. Por fim, é importante salientar que o diário de Walmir Ayala se abre, como nenhum outro de sua época, para uma representaçâo das relaçôes homoeróticas, sua escrita, corajosamente, coloca em cena relacionamentos 
que, até entăo, năo tinham sua existência atestada senáo pelos escritos médicos, pelas páginas policiais ou estereotipadas através de textos literários escritos por autores que conheciam a homossexualidade somente através das duas instâncias anteriores. O diarista, talvez por ter em mente a aura de imoralidade e superficialidade que tradicionalmente se atribuía ao homossexual, busca sempre colocar as relaçóes físicas que descreve num contexto maior, sobretudo associando-as ao amor, em interaçóes que ultrapassem o imediatismo do corpo.

Em conclusâo, creio que seja importante notar que, de um modo geral, na forma como os dois diaristas lidam com o corpo, a referência que se faz é, quase sempre, ao corpo do outro. É como se o homossexual, além de nâo ter direito a voz e a representaçâo simbólica, também náo tivesse direito a uma existência corpórea, e estivesse fadado a se ver senăo no corpo do outro. Assim, nas poucas vezes que emerge um corpo nesses escritos diarísticos, é o corpo amado, o corpo que se deseja mas que, ao mesmo tempo, logo se esvanece. O próprio corpo, se aparece - a meu ver algo que acontece apenas no texto de Ayala -, é para lembrar de um corpo que está em vias de se dissipar, que se destina a deixar de existir do modo mais doloroso possível. 


\section{REFERÊNCIAS}

AYALA, Walmir. A fuga do arcanjo: diário III. Rio de Janeiro: Brasília/Rio, 1976.

AYALA, Walmir. Diário I. Difícil é o reino. Rio de Janeiro: GRD, 1962.

AYALA, Walmir. O visível amor: diário II. Rio de Janeiro: José Álvaro, 1963.

BARCELLOS, Sérgio. O corpo nos diários pessoais: presença e latência. In: MONTEIRO, Maria Conceiçăo; CHIARA, Ana Cristina; SANTOS, Francisco Venceslau. (Org.). Escritas do corpo. Rio de Janeiro: Caetés, 2011. P. 76-86.

BRAUD, Michel. La forme des jours. Pour une poétique du journal personnel. Paris: Seuil, 2006.

CABANĖS, Jean-Louis. L'écrivain et ses travaux au miroir des journaux intimes. In: DUFIEF, Pierre-Jean. (Org.) Les journaux de la vie littéraire: Actes du colloque de Brest 18-19 octobre 2007. Rennes: Presses Universitaires de Rennes, 2009. Disponível em: http://books.openedition.org/pur/38896. Acesso em: 26 nov. 2016.

CARDOSO, Lúcio. Diários. Organizaçăo, apresentaçăo, cronologia, estabelecimento de texto e notas de Ésio Macedo Ribeiro. Rio de Janeiro: Civilizaçăo Brasileira, 2012.

KRAUTHAKER, Marion. S'écrire pour mieux mourir. Les souvenirs de l'hermaphrodite Herculine Barbin. In: VIOLLET, Catherine; CONSTANTIN, Danielle (Org). Genre, sexes, sexualités. Que disent les manuscrits autobiographiques? Mont-Saint-Aignan: Presses Universitaires de Rouen et du Havre, 2016. P. 17-26. 